\title{
Oculoauriculovertebral spectrum with radial defects: a new syndrome or an extension of the oculoauriculovertebral spectrum? Report of fourteen Brazilian cases and review of the literature
}

\author{
Siulan Vendramini* ${ }^{* 1}$, Antonio Richieri-Costa ${ }^{1}$ and Maria Leine Guion-Almeida ${ }^{1}$ \\ ${ }^{1}$ Department of Clinical Genetics, Hospital de Reabilitação de Anomalias Craniofaciais, Universidade de São Paulo \\ (USP), Bauru, Brazil
}

The first and second branchial arches are embryonic primordium that contributes to craniofacial development. Interferences in normal development of these structures result in variable maxillary, mandibular, and ear abnormalities. These anomalies can be isolated or part of some known and unknown conditions, among them, the oculoauriculovertebral spectrum (OAVS). Malformations of the external ear or microtia are mandatory features of the OAVS and occur as an isolated malformation (population

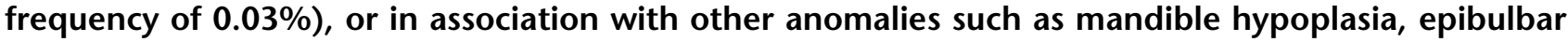
dermoids, and spinal vertebral defects. Extreme variability of phenotypic manifestations is the main feature of the OAVS and, developmental anomalies are not restricted to facial structures. Cardiac, pulmonary, renal, skeletal, and central nervous system involvements have been observed in patients presented with this condition. Radial defects, although rare, have been reported. In this study, we report on the clinical aspects of 14 Brazilian patients with first and second branchial arches abnormalities associated with radial defects and we compared these data with those of 26 cases in the literature. We postulate that radial defects associated with OAVS might represent a subset within this spectrum. European Journal of Human Genetics (2007) 15, 411-421. doi:10.1038/sj.ejhg.5201770; published online 7 February 2007

Keywords: oculoauriculovertebral spectrum; Goldenhar syndrome; hemifacial microsomia; radial defects; sensorioneural hearing loss; inner ear malformation

Introduction

The association of oculoauriculovertebral spectrum (OAVS) and radial defects have been reported since $1929^{1-9}$ and, the early literature on the issue used to quote radial anomalies as a clinical feature belonging to the OAVS; however, some authors have considered it as a unique

*Correspondence: $\operatorname{Dr}$ S Vendramini, Clinical Genetic, Hospital de Reabilitação de Anomalias Craniofaciais, Universidade de São Paulo, Rua Silvio Marchione 3-20, CEP 17012-230, SP, Bauru, Brazil.

Tel: + 55014 32358022; Fax: + 55014 32347818;

E-mail: siulan@centrinho.usp.br

Received 16 August 2006; revised 2 November 2006; accepted 21 November 2006; published online 7 February 2007 association, representing a 'new' condition within the spectrum (OMIM 141400). ${ }^{7,10}$ Taking into account the clinical manifestation of the OAVS with radial defects, and the OAVS without limb involvement, there are no differences concerning craniofacial and extracraniofacial anomalies when both are compared. To date, about 32 cases on OAVS and radial defects have been reported, and in 26 instances, the data were informative..$^{3,5-8,11-26}$ Here, we describe 14 Brazilian patients with clinical signs of OAVS associated with several radial defects (Figures $1-14 a-d$ ). Hearing evaluation through audiometry and brainstem evoked response, and radiological evaluation through temporal bone CT scan, were performed in all patients. 
412 $S$ Vendramini et al

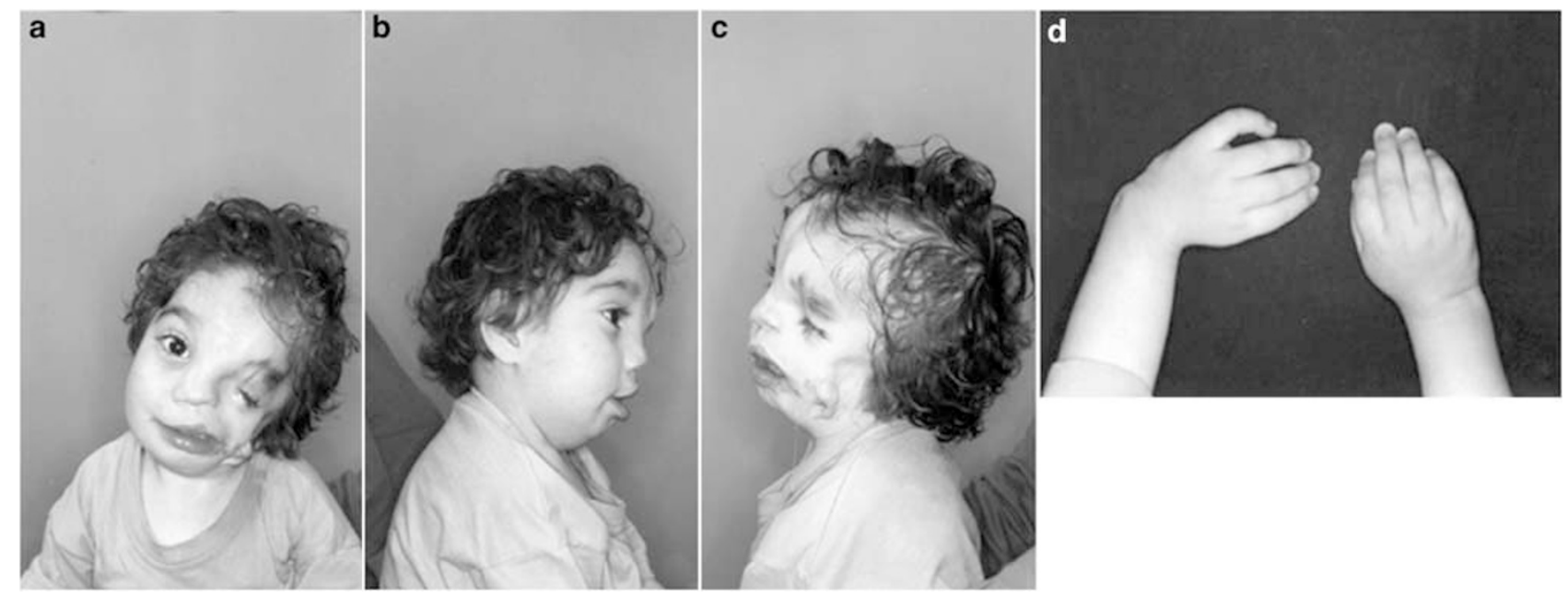

Figure $1(\mathbf{a}-\mathbf{d})$ - Clinical aspects of the face and upper limbs of patient 1.
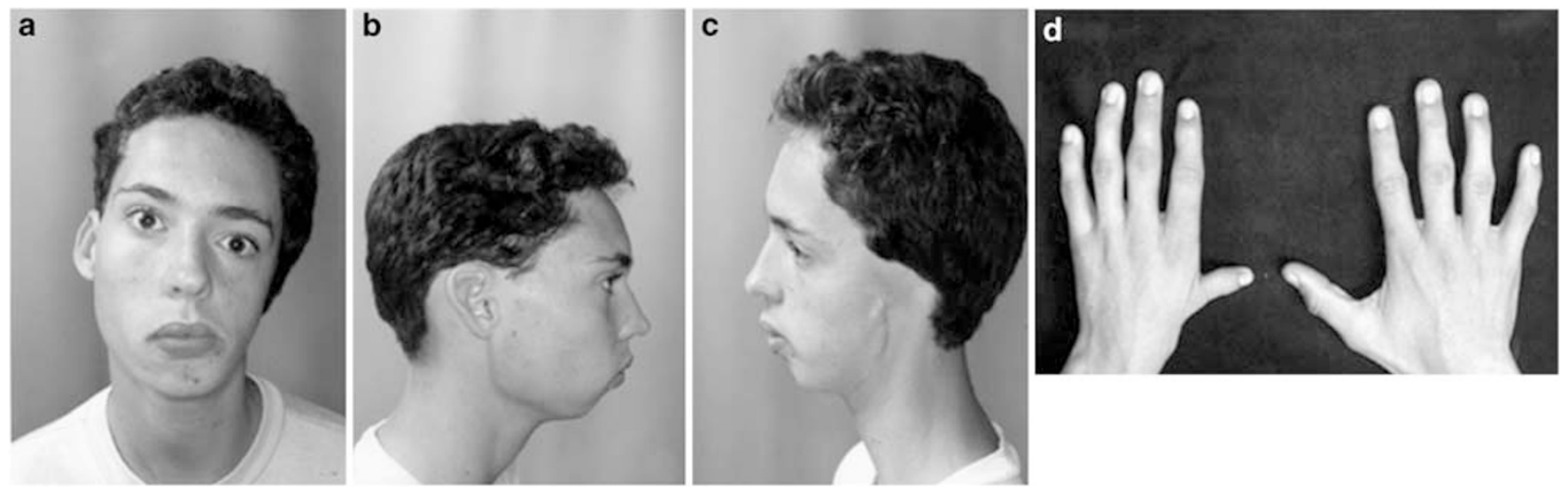

Figure $2(\mathbf{a}-\mathbf{d})$ - Clinical aspects of the face and upper limbs of patient 2.

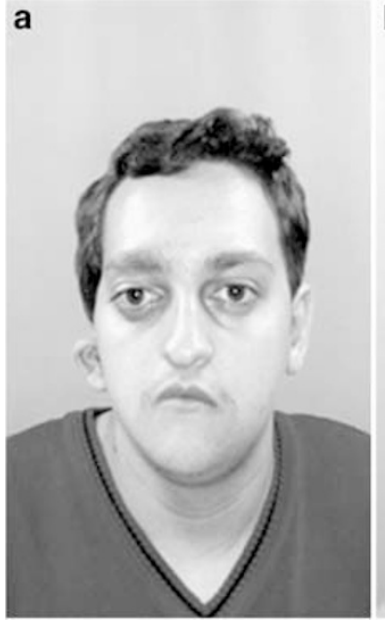

b

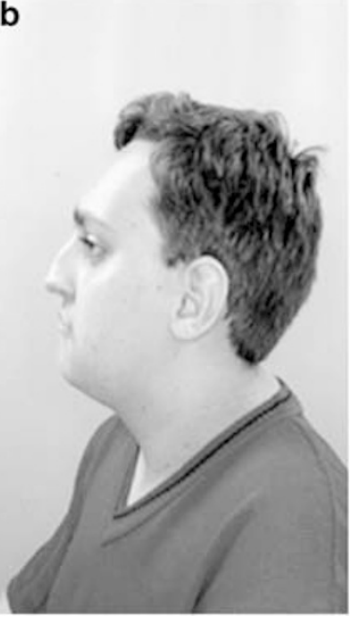

C
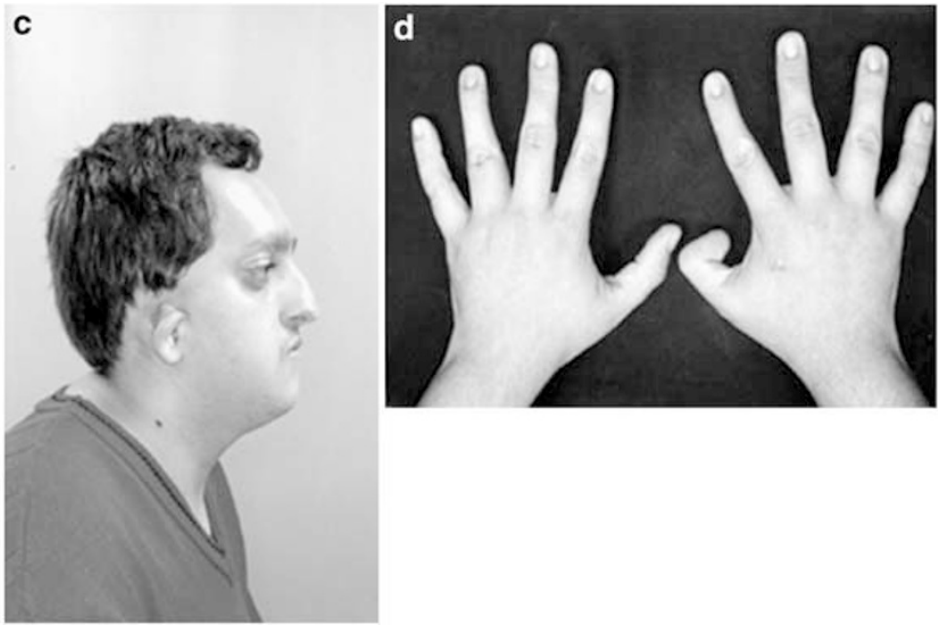

Figure $3(\mathbf{a}-\mathbf{d})-$ Clinical aspects of the face and upper limbs of patient 3. 

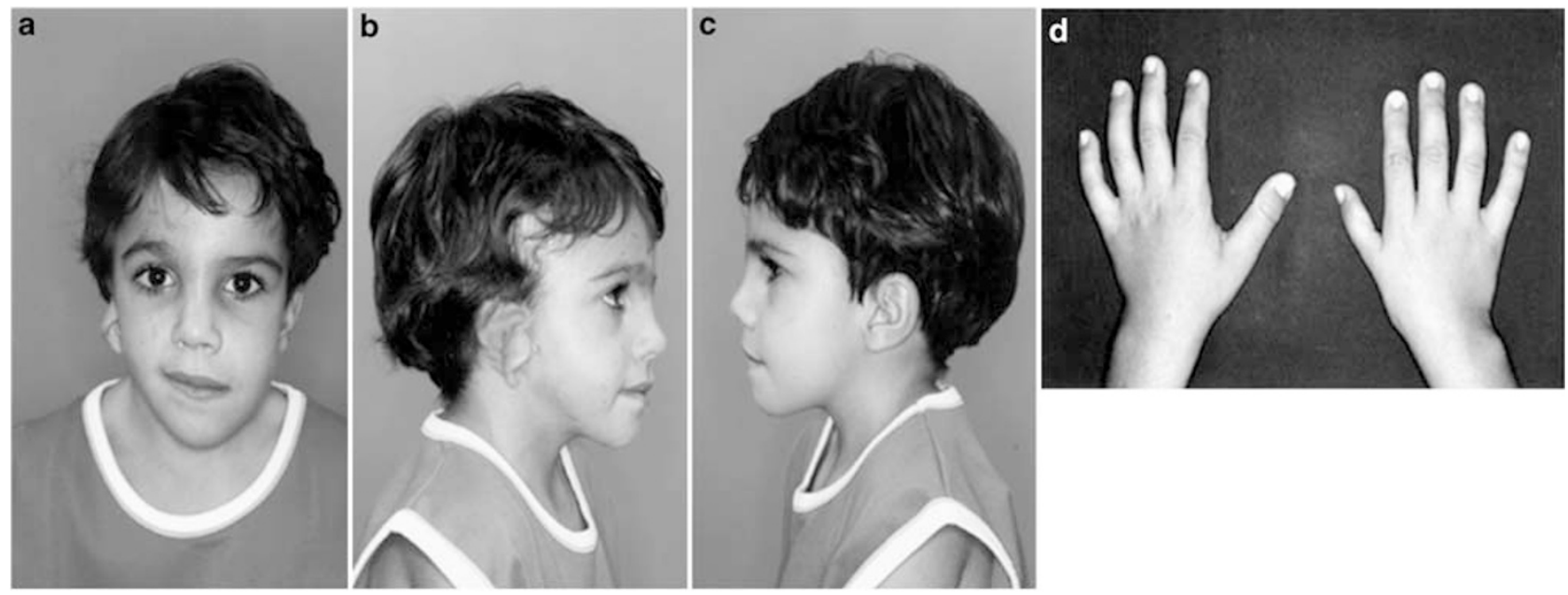

Figure $4(\mathbf{a}-\mathbf{d})$ - Clinical aspects of the face and upper limbs of patient 4.
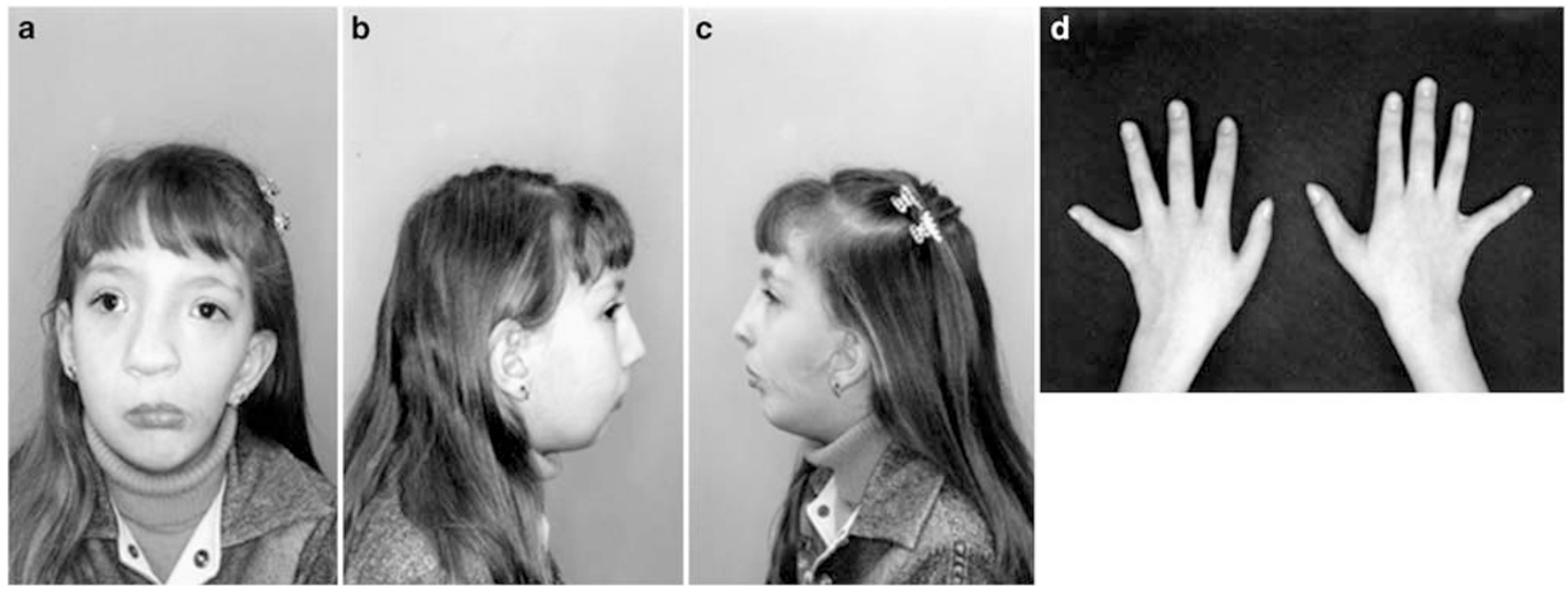

Figure $5(\mathbf{a}-\mathbf{d})-$ Clinical aspects of the face and upper limbs of patient 5.
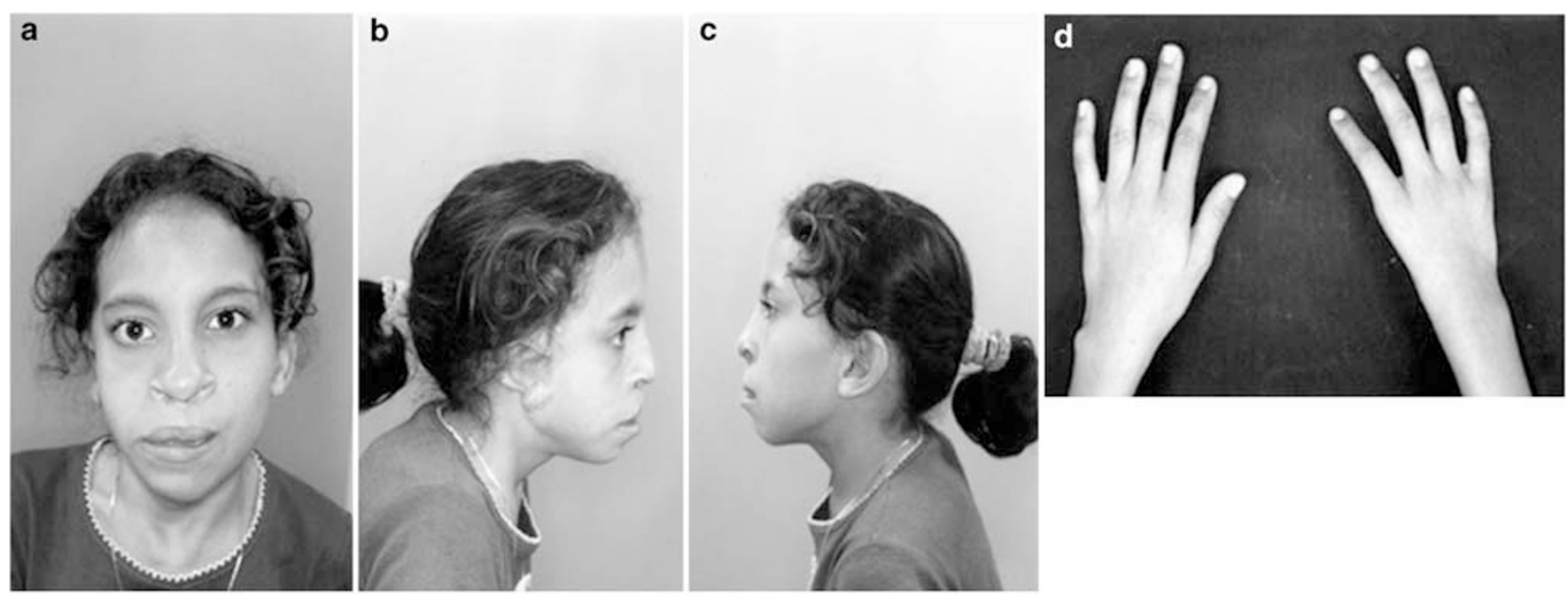

Figure $6(\mathbf{a}-\mathbf{d})$ - Clinical aspects of the face and upper limbs of patient 6 . 
414 $S$ Vendramini et al
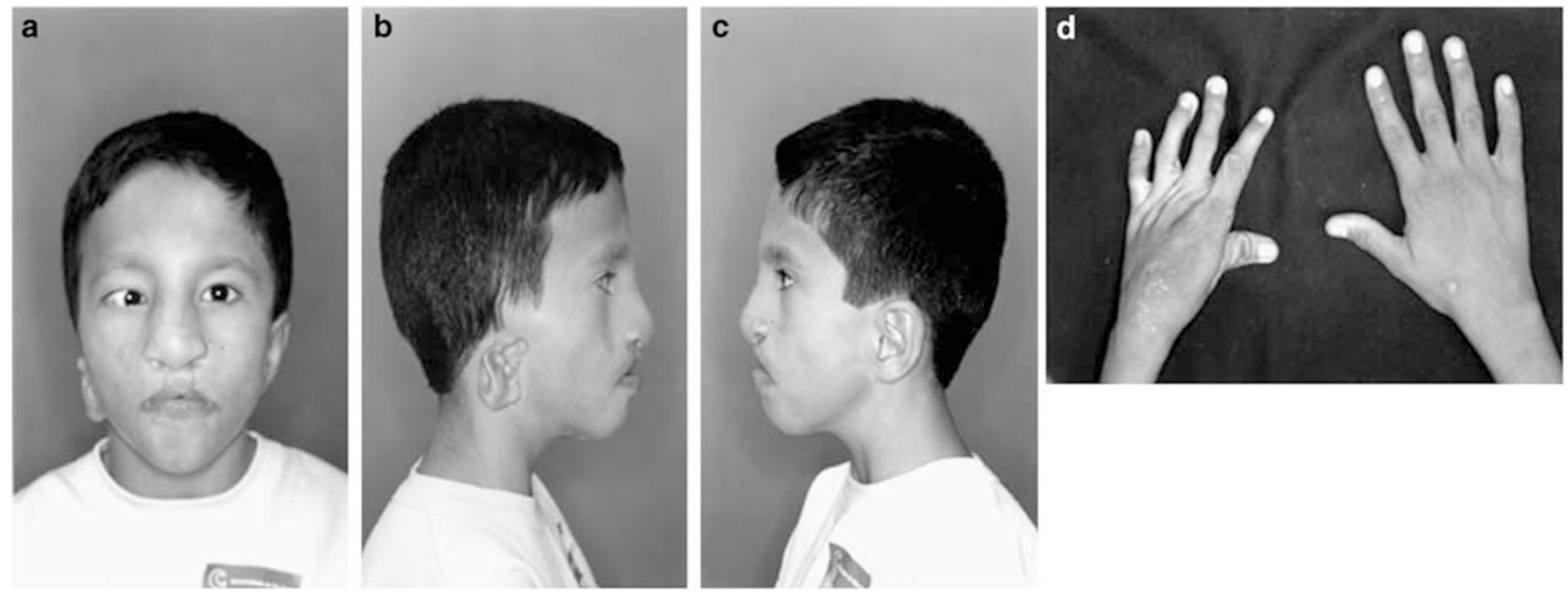

Figure $7(\mathbf{a}-\mathbf{d})-$ Clinical aspects of the face and upper limbs of patient 7.

a

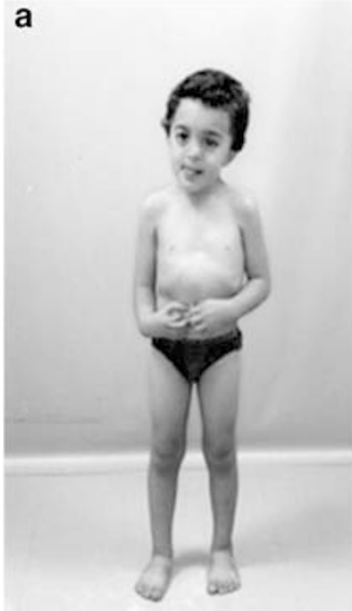

b

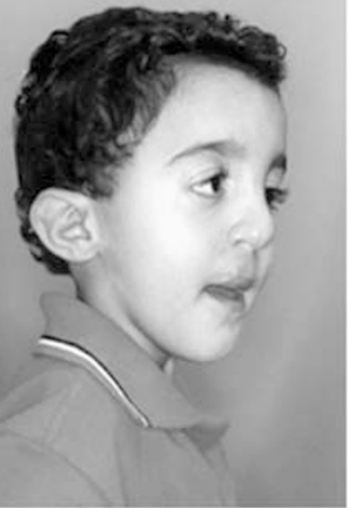

c

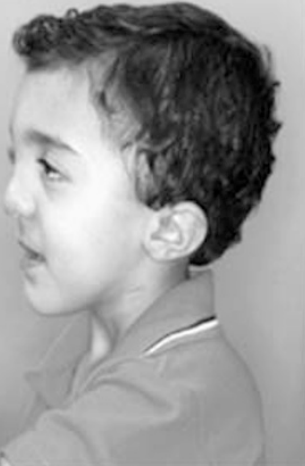

z)

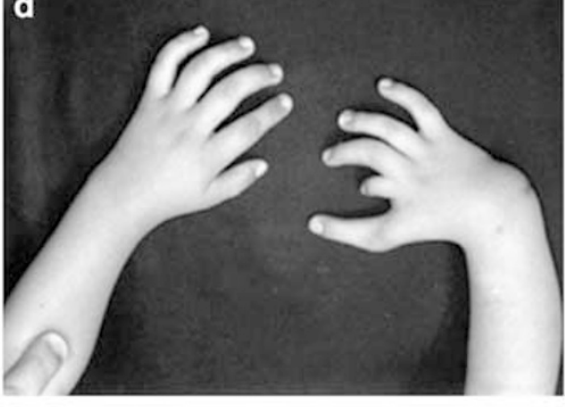

Figure $8(\mathbf{a}-\mathbf{d})$ - Clinical aspects of the face and upper limbs of patient 8.

a

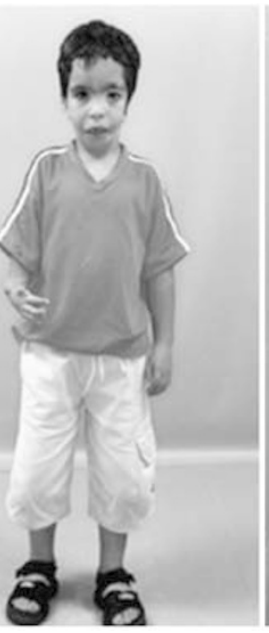

b

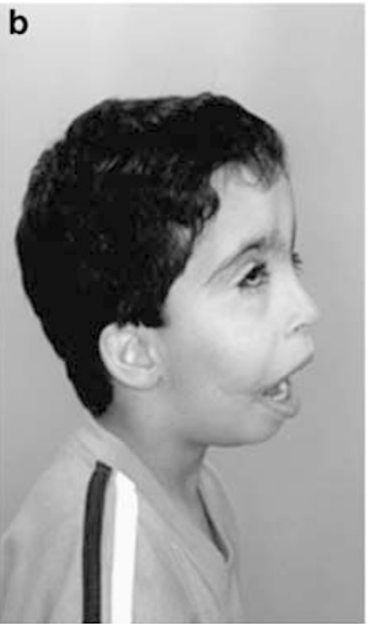

c

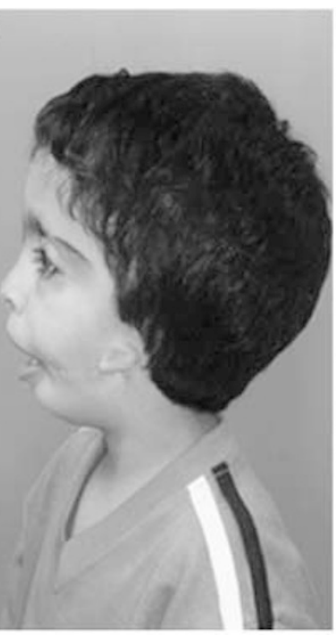

d

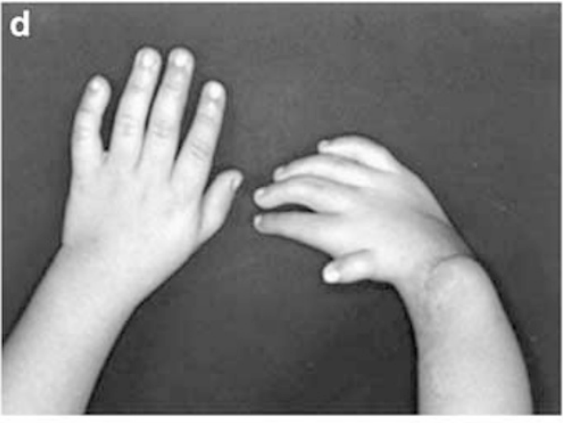

Figure $9(\mathbf{a}-\mathbf{d})$ - Clinical aspects of the face and upper limbs of patient 9. 

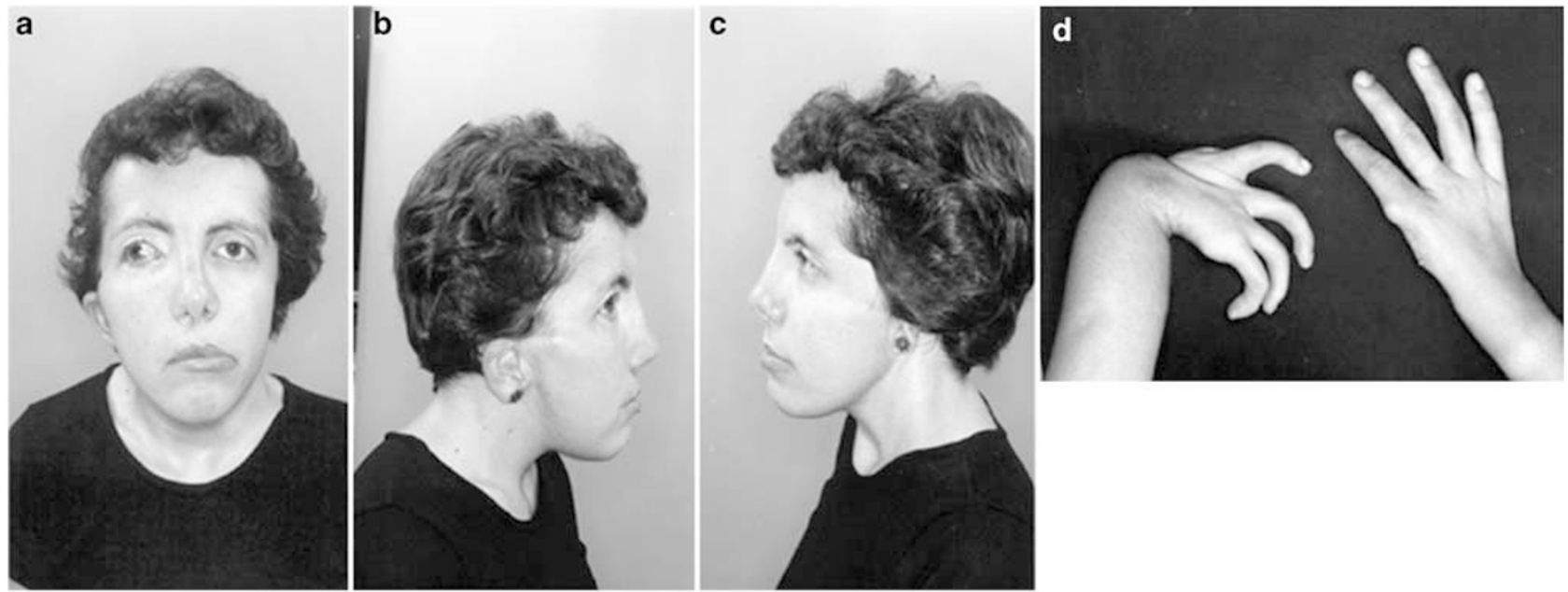

Figure $10(\mathbf{a}-\mathbf{d})-$ Clinical aspects of the face and upper limbs of patient 10.

a

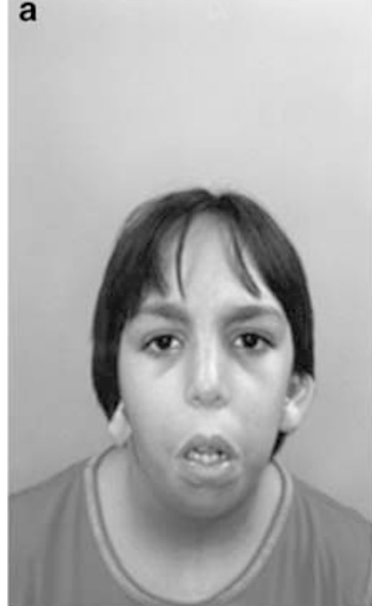

b

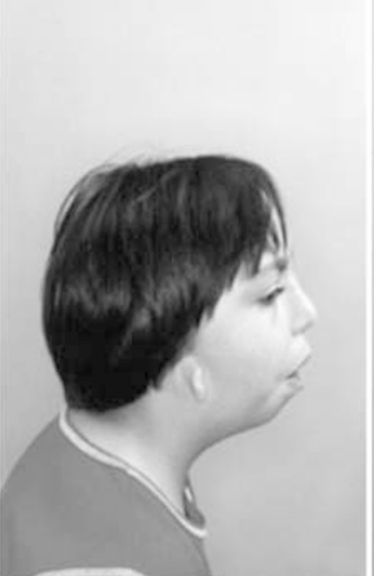

c

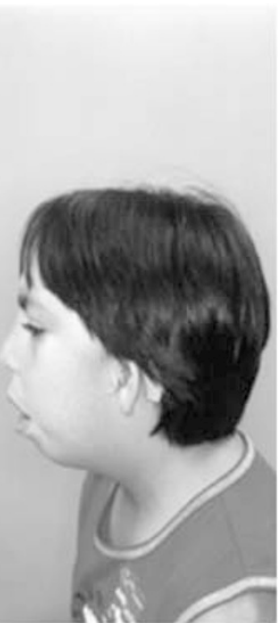

d

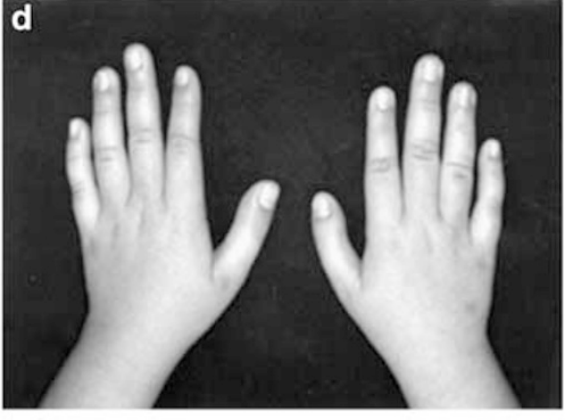

Figure $11(\mathbf{a}-\mathbf{d})$ - Clinical aspects of the face and upper limbs of patient 11.
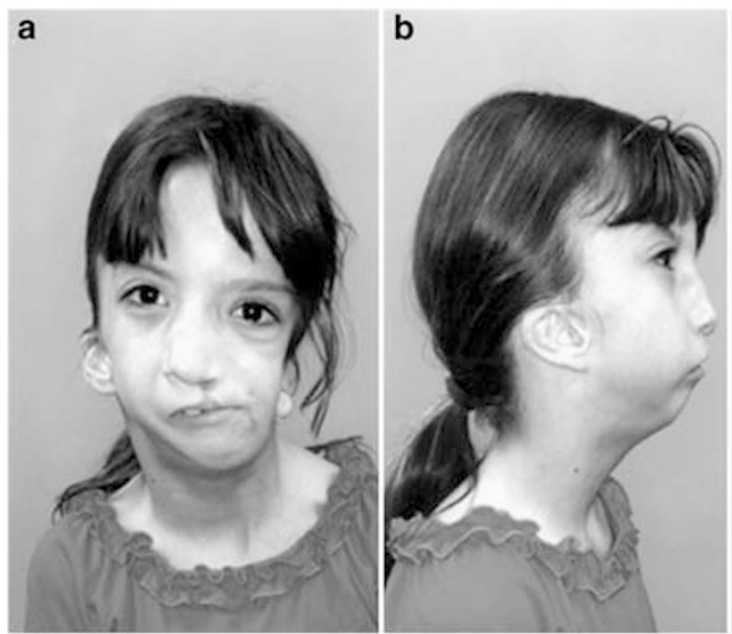

c

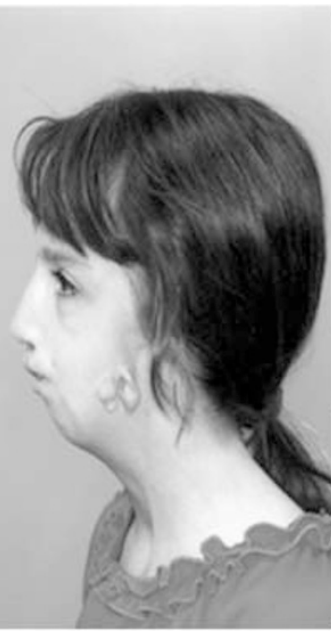

d

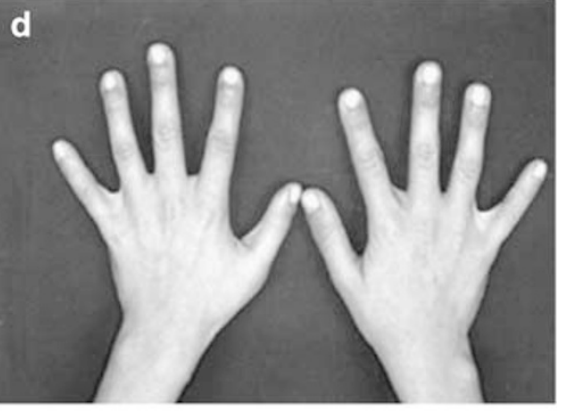

Figure 12 (a-d) - Clinical aspects of the face and upper limbs of patient 12 . 

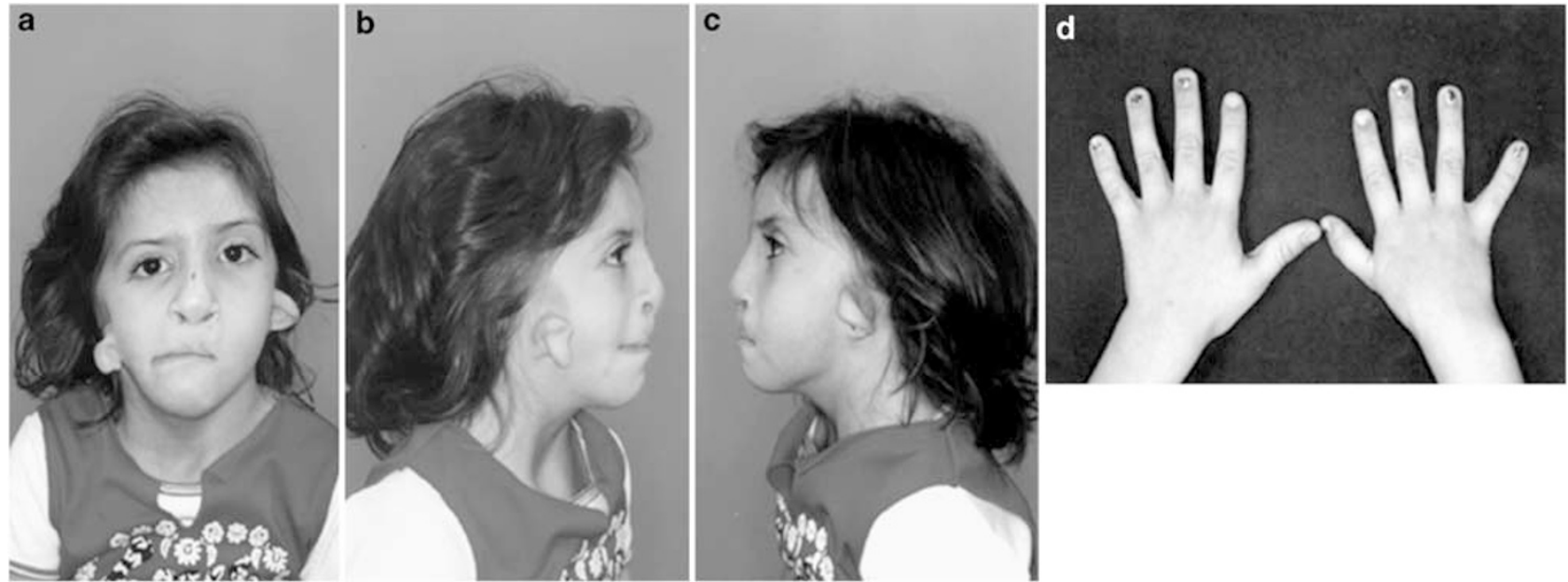

Figure 13 (a-d) - Clinical aspects of the face and upper limbs of patient 13.

a

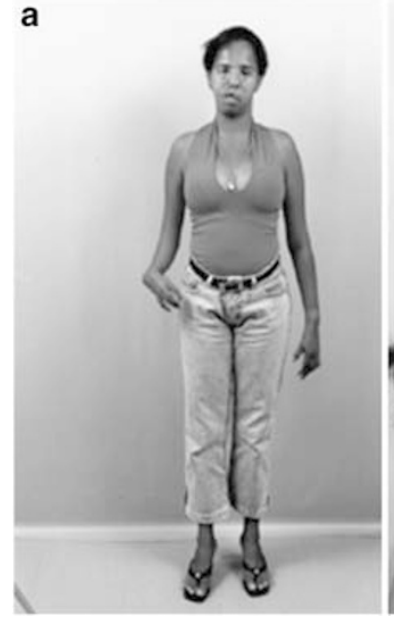

b

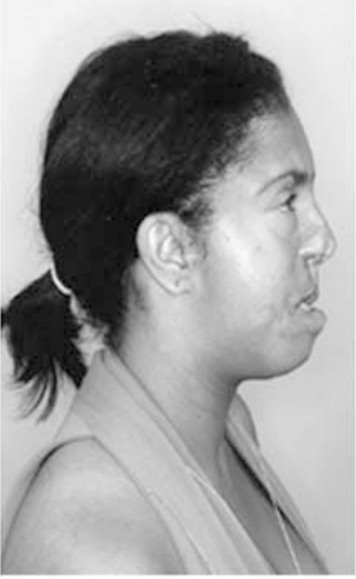

C

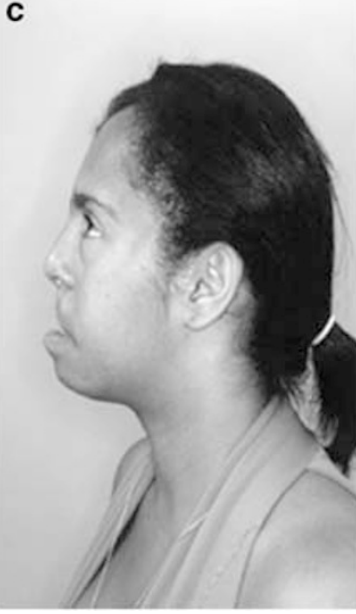

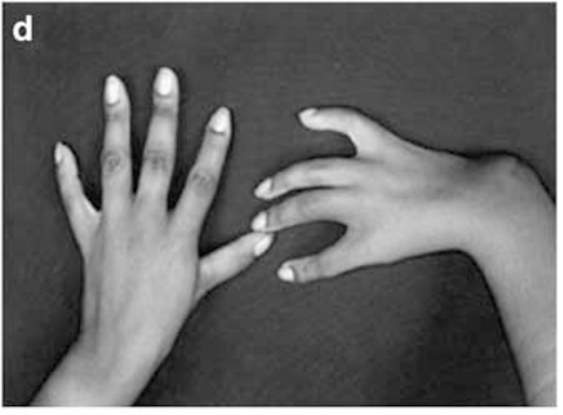

Figure $14(\mathbf{a}-\mathbf{d})$ - Clinical aspects of the face and upper limbs of patient 14 .

The relationship among clinical, audiological, and radiological findings is discussed.

\section{Materials and methods}

We selected a sample of 24 cases from the Clinical Genetic Service with the Hospital de Reabilitação de Anomalias Craniofaciais of the University from São Paulo - Bauru-SP, Brazil. Ten cases were excluded due to interruption of treatment, social problems, or premature death. The remaining concerns the present sample that involves 14 patients (Figures $1-14 \mathrm{a}-\mathrm{d}$ ). Minimal criteria for propositi to be included in the casuistic were the presence of asymmetrical external ear malformation and radial defects. The protocol for evaluation of the patients included: identification data; prenatal, perinatal, and family history.
Clinical evaluation included: general examination with particular concern to the classification of the external ear defect and the facial type of cleft. Complementary evaluation included: skull, facial, and upper limbs X-rays; temporal bone CT scan; and hematological and G-banded chromosome studies. Audiological evaluation included puretone audiometry, speech audiometry, tympanometry, stapedius reflex measurement, and brainstem evoked response. In some ears, it was not possible to perform the tympanometry and stapedius reflex measurement owing to malformation. Malformations of the external ear were graded according to modified system from Meurman; ${ }^{27}$ atypical facial clefts were classified according to Tessier system; ${ }^{28}$ and hearing loss type was classified according to Katz. ${ }^{29}$ The clinical aspects of our patients (14 cases) and of those described in the literature (26 patients) were compared. 


\section{Results}

From the total of the sample, eight patients were male and six female (sex-ratio 1:1); mean age was 11.1 years (range, $1-25$ years); mean maternal age was 24.1 years; and mean paternal age was 28.7 years. There was no history of exposure neither to known teratogenic agents nor maternal diseases. All cases were isolated with negative family history for related features. No parental consanguinity was observed. Hematological and cytogenetic studies were normal in all patients.

From the informative reviewed cases, the sex ratio was 1:1; mean age was 5.5 years (range, 1 month to 25 years); mean maternal age was 30.3 years; and mean paternal age was 37.2 years. Maternal diabetes or gestational diabetes was present in four cases; cocaine exposure was reported in one case. Twenty-four out of twenty-six reported cases were isolated; familial recurrence was described once and, parental consanguinity was reported in one instance.

\section{Clinical findings}

The main clinical findings of our cases and those previously reported in the literature are listed in Table 1.

\section{Radial defects}

Varied defects involving the radial developmental field occurred in all patients studied.

The most common anomalies observed were hypoplasia of the thumb and hypoplasia and/or agenesis of the radio. The radial defects observed with less frequency were thumb agenesis, preaxial polydactyly, and triphalangeal thumb.

Taking into account the literature cases, agenesis of the thumb and hypoplasia and/or agenesis of the ratio were most common, whereas trifalangeal thumb, preaxial polydactyly, and thumb hypoplasia were rarely observed.

\section{Laterality}

In relation to facial anomalies, unilateral facial involvement was observed in eight out of 14 patients $(57.1 \%)$ : right-sided in five instances (62.5\%) and left-sided in three $(37.5 \%)$. Bilateral facial involvement was present in six out of 14 patients $(42.8 \%)$.

Considering the radial defects, the unilateral radial involvement was observed in eight out of 14 cases: rightsided involvement in five instances $(61.5 \%)$ and left-sided in three $(37.5 \%)$. Bilateral involvement was present in six cases $(42.8 \%)$.

From the eight patients with unilateral facial involvement, five $(62.5 \%)$ had ipsilateral upper limbs defects; one $(12.5 \%)$ had contralateral upper limb defects; and two (25\%) had bilateral upper limbs involvement. From the six patients with bilateral facial involvement, four (66.7\%) had also bilateral involvement of the upper limbs and two (33.3\%), had unilateral upper limbs defects.

From the informative reviewed cases, unilateral facial involvement was described in 20 of 24 cases: right-sided in
12 instances and left-sided in eight. Bilateral involvement was present in four patients. In relation to radial defects, unilateral involvement was observed in 23 out of 26 cases: right-sided involvement in 12 instances and left-sided in 11. Bilateral involvement was present in three cases. From the 20 patients with specific unilateral facial involvement, 14 had ipsilateral upper limbs defects; three had bilateral upper limbs involvement; and five had contralateral upper limb defects. All patients with bilateral facial involvement had unilateral upper limbs involvement.

\section{Ears structural involvement and hearing loss}

In relation to external ear anomalies, 20 out of 28 ears presented microtia. Type I was the most common and it was observed in $10(50 \%)$ out of 20 ears. Type II microtia was observed in two (10\%) out of 20 ears, and type III microtia was observed in eight (40\%) out of 20 ears. Middle ear malformations were detected in four $(20 \%)$ out of 20 ears with microtia; inner ear malformations were detected in four (20\%); and middle and inner ear malformations were detected in 11 (55\%). Structural middle and/or inner abnormalities were absent in one ear with microtia. From the 10 ears with type I microtia, two (20\%) had middle ear malformation; three (30\%) had inner ear malformation; four (40\%) had both, middle and inner malformation; and one $(10 \%)$ had no malformation of middle and/or inner ear. From the two ears type II with microtia, one (50\%) had middle ear malformation; and one (50\%) had inner ear malformation. From the eight ears with type III microtia, one $(12.5 \%)$ had middle ear malformation and seven $(87.5 \%)$ had middle and inner ear malformation.

Taking into account, the external ear anomalies of the literature sample, 30 out of 50 ears presented microtia. Type I was the most common and it was reported in 16 (53.3\%) out of 30 ears. Type II microtia was reported in two (6.7\%) out of 30 ears, and type III microtia was observed in six $(20 \%)$ out of 30 ears. Anotia was reported in two $(6.7 \%)$ out of 30 ears and, the type was not specified in four (13.3\%) out of 30 ears. Evaluation of middle and/or inner ear was performed in five out of 30 ears with microtia (four with type I and one with type II). Structural middle ear malformations were described in one (20\%) out of five ears; structural inner ear malformations were reported in three (60\%); and structural middle and inner ear malformations were detected in one (20\%). From the four ears with type I microtia, one had middle ear malformation and three had inner ear malformation. Structural middle and inner ear malformation was observed in one ear with type II microtia.

In relation to hearing loss, 27 out of 28 ears showed hearing loss. All ears with microtia (20 ears) had hearing loss: four (20\%) presented conductive hearing loss; six (30\%) presented mixed hearing loss; eight (40\%) presented sensorioneural hearing loss. It was not possible to conclude the type of hearing loss in two (10\%) out of 20 ears with 
Table 1 Main clinical features reported in our patients compared with the previously described cases

\begin{tabular}{|c|c|c|c|c|c|c|c|c|c|c|c|c|c|c|c|c|c|c|c|c|}
\hline & \multicolumn{16}{|c|}{ Our patients } & \multicolumn{2}{|c|}{ Literature $^{a}$} & \multicolumn{2}{|c|}{ Total of the sample } \\
\hline & 1 & 2 & 3 & 4 & 5 & 6 & 7 & 8 & 9 & 10 & 11 & 12 & 13 & 14 & $f$ & $P$ & $f$ & $P$ & f & P \\
\hline \multicolumn{20}{|l|}{ General } & \\
\hline Parental consnaguinity & - & - & - & - & - & - & - & - & - & - & - & - & - & - & $0 / 14$ & 0 & $1 / 26$ & $3.8 \%$ & $1 / 40$ & $2.5 \%$ \\
\hline & - & - & - & - & - & - & - & - & - & - & - & - & - & - & $0 / 14$ & 0 & $1 / 26$ & $3.8 \%$ & $1 / 40$ & $2.5 \%$ \\
\hline & + & - & - & - & - & + & - & - & & + & - & - & + & - & $5 / 14$ & $35.7 \%$ & 2 & & $7 / 22$ & $31.8 \%$ \\
\hline & + & - & - & - & - & + & + & - & + & + & + & - & + & - & $7 / 14$ & $50 \%$ & 21 & $25 \%$ & $9 / 22$ & $0.9 \%$ \\
\hline Chromosomes & $\mathrm{nl}$ & $\mathrm{nl}$ & $\mathrm{nl}$ & $\mathrm{nl}$ & $\mathrm{nl}$ & $\mathrm{nl}$ & $\mathrm{nl}$ & $\mathrm{nl}$ & $\mathrm{nl}$ & $\mathrm{nl}$ & $\mathrm{nl}$ & $\mathrm{nl}$ & $\mathrm{nl}$ & $\mathrm{nl}$ & $0 / 14$ & 0 & $0 / 26$ & 0 & 0 & 0 \\
\hline \multicolumn{21}{|l|}{ Clinical evaluation } \\
\hline & + & + & + & + & + & + & + & - & + & + & + & + & + & + & $13 / 14$ & $92.9 \%$ & $21 / 26$ & $80.8 \%$ & $34 / 40$ & $85 \%$ \\
\hline & + & - & - & - & - & - & - & + & - & - & - & - & - & - & $2 /$ & & & & & $10 \%$ \\
\hline & - & - & - & - & + & - & - & - & + & - & - & + & - & - & 31 & & $9 /$ & & & $30 \%$ \\
\hline & - & - & - & - & - & - & - & - & + & - & - & - & - & + & & & & & & \\
\hline $\mathrm{Cl}$ & + & - & - & - & + & + & + & + & - & + & - & + & + & + & $9 / 14$ & 64.3 & $5 / 26$ & 19.2 & $14 / 40$ & $35 \%$ \\
\hline & & + & + & - & - & - & - & - & - & - & + & - & - & - & $3 / 14$ & & $4 / 26$ & & $7 / 40$ & $17.5 \%$ \\
\hline & + & - & - & - & + & - & - & - & - & - & - & - & + & + & $4 / 1$ & & $1 /$ & & & $12.5 \%$ \\
\hline & + & + & + & + & + & + & + & - & + & + & + & + & + & + & $13 / 1$ & 92. & $20 /$ & & $33 /$ & $82.5 \%$ \\
\hline & - & - & - & - & + & - & - & - & + & - & - & - & - & - & $2 / 1$ & & & & & $10 \%$ \\
\hline & - & - & - & + & - & - & + & - & + & - & + & + & - & + & & & & & & $55 \%$ \\
\hline & + & + & + & + & + & + & + & + & + & + & + & + & + & + & & & 6/ & & & $100 \%$ \\
\hline & + & + & + & + & + & + & - & - & + & + & + & + & + & - & 4 & & 2 & & $13 /$ & $72.2 \%$ \\
\hline & + & + & + & + & - & + & + & + & + & + & - & + & + & - & & & & & & $77.8 \%$ \\
\hline & + & + & + & + & + & + & + & + & + & + & + & + & + & + & & & $9 /$ & & & $95.8 \%$ \\
\hline & + & + & + & + & + & + & - & - & + & + & - & + & + & + & $11 / 14$ & 78. & $19 / 2$ & & & $70 \%$ \\
\hline & + & + & + & + & + & + & + & + & + & + & + & + & + & + & $14 / 14$ & 100 & $26 / 2$ & & 0 & $100 \%$ \\
\hline ities & - & + & NA & NA & NA & NA & NA & NA & - & + & - & - & NA & NA & $2 / 6$ & 33.3 & $13 /$ & & $15 /$ & \\
\hline & - & NA & NA & NA & - & NA & NA & NA & - & NA & - & NA & NA & NA & 0 & 0 & & & & $4.4 \%$ \\
\hline & - & + & - & - & - & - & - & - & - & - & + & - & - & - & & & & & & $15.8 \%$ \\
\hline rmalities & NA & NA & + & NA & NA & NA & NA & NA & NA & NA & NA & NA & NA & NA & $1 / 1$ & & $1 / 2$ & & & $7.4 \%$ \\
\hline & - & - & - & - & - & - & - & - & - & - & - & - & + & - & $1 / 14$ & 7.1 & $3 / 2$ & 11.5 & $4 / 40$ & $10 \%$ \\
\hline & + & - & - & + & - & + & + & + & - & + & - & + & + & - & $8 / 14$ & $57.1 \%$ & $4 / 18$ & $22.2 \%$ & $12 / 32$ & $37.5 \%$ \\
\hline Mental retardation & - & - & - & - & - & - & - & + & - & - & - & - & + & - & $2 / 14$ & $14.3 \%$ & $N R$ & $\mathrm{NR}$ & $2 / 14$ & $14.3 \%$ \\
\hline
\end{tabular}

M: male; F: female; +: present sign; -: absent sign; nl: normal; NA: not avaliable; NR: not reported; f: frequency; P: percentage.

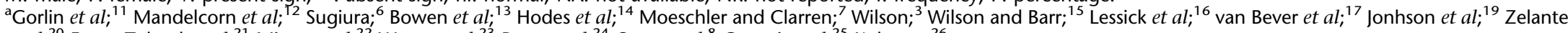
et $a l ;{ }^{20}$ Ewart-Toland et al; $;^{21}$ Miura et al; ${ }^{22}$ Wang et al; ${ }^{23}$ Pane et al; ${ }^{24}$ Oner et al; ${ }^{8}$ Castori et al; ${ }^{25}$ Kokavec. ${ }^{26}$ 
microtia. From the eight ears without microtia, normal hearing was present in one ear; conductive hearing loss in three; mixed hearing loss in two; and sensorioneural hearing loss in two. Taking into account, the type of microtia and the type of hearing loss, from 10 ears with type I microtia, four (40\%) had conductive hearing loss; two (20\%) had mixed hearing loss; and four (40\%) had sensorioneural hearing loss. The two ears with type II microtia had sensorineural hearing loss. From eight ears with type III microtia, four (50\%) had mixed hearing loss; two (25\%) had sensorioneural hearing loss; and in two $(25 \%)$, the type of hearing loss was not conclusive.

From the reviewed cases of the literature, only 14 ears had audiological evaluation. Conductive hearing loss was present in three out of 14 ears and mixed hearing loss in one ear. The hearing loss type was no conclusive in eight out of 14 ears and, the hearing was normal in two ears.

\section{Discussion}

OAVS, or Goldenhar syndrome, is a well-recognized condition characterized by variable degree of uni- or bilateral involvement of craniofacial structures involving first and second branchial arches, ocular anomalies and vertebral defect. Clinically, it ranges from isolated microtia with or without mandibular hypoplasia, to a more complex phenotype with skeletal, cardiac, renal, pulmonary, and central system manifestations. ${ }^{2,5}$ The pathogenetic mechanisms involved have been a matter of controversy and theories ${ }^{2,30,31}$ but so far, no definitive causal agent could be found. It has been postulated that the Goldenhar syndrome represents a defect of blastogenesis ${ }^{32}$ that could be attributed to interferences in cephalic neural crest cell migration, ${ }^{33}$ however, in some cases of OAVS with multi systemic malformations, the involvement of several developmental fields do not sustain a localized damage.

The OAVS with radial defects characterizes a subset within the OAVS mainly involving uni- or bilaterally the first branchial arches and limb primordium. The main signs include external, middle, and inner ear malformations; facial asymmetry, orofacial clefts, mandible hypoplasia, and radial defect, which is a 'sine qua non' anomaly for clinical diagnosis. Inner ear involvement was frequently observed in OAVS with radial defects $(78.6 \%$ of cases and, $80 \%$ of cases of literature sample). This type of anomaly has been reported once in patients with the Goldenhar syndrome with a low frequency (36\% of cases). ${ }^{34}$ The high frequency of inner ear involvement in patients with OAVS and radial anomalies could suggest that this is a common clinical sign of this subset.

The inner ear anomalies have been reported in patients with microtia but without correlation with the degree of microtia. ${ }^{35}$ In the patients here reported, type I and type III microtia were most common, corresponding to 50 and
$40 \%$, respectively, and in both, a high incidence of inner ear malformation associated, or not with middle ear malformation, was noted -70 and $87.5 \%$, respectively, showing that the severity of the external ear malformation was not predictive of inner structural anomalies. These data suggest that type I and type III microtia, in OAVS, could be related to inner ear involvement. It has to be stressed that in patients with bilateral ear involvement, the association of type I and type III microtia was most common. In the literature, type I microtia was most frequent $(53.3 \%)$ and, such as in our sample, a high incidence of inner ear malformation was reported, too. ${ }^{3,6-8,11-17,19-24}$ Rollnick and Kaye ${ }^{36}$ found that, type II microtia was most frequent $(42 \%)$ in familial cases with hemifacial microssomia and in variants without radial anomalies, but the inner ear evaluation was not performed. In our sample, sensorioneural hearing loss was most common in type I microtia (40\%) and in type II microtia (100\%) showing that the type of microtia had no predictive value for the type of hearing loss. These data suggest that the sensorioneural hearing loss is a sign related to the OAVS with radial anomalies. In the previously reported cases with this condition, in 14 patients that were submitted to audiological evaluation, hearing loss was detected in 12 .

The low weight and short stature in patients show that these clinical findings are a part of the phenotypic spectrum of OAVS with radial defects. Tasse et al, ${ }^{37}$ in a sample of 53 patients with OAVS, found that anomalies of extremities, such as, thumb hypoplasia, were significantly associated with the short stature.

Systemic anomalies represented by cardiovascular and pulmonary defects and, anal anomalies, in our sample, were also observed in OAVS, however, the real incidence of these anomalies is not well known. ${ }^{2,4,5,20}$ In relation to OAVS with radial defects, the presence of some systemic anomalies did not exceed that observed in previously reported cases with OAVS except, the cardiovascular defect that was detected in $33.3 \%$ of the patients here studied and in $92.8 \%$ of the cases in the literature. $3,6-8,11-17,19-24$ These data support the hypothesis that cardiovascular defects are a frequent clinical sign of OAVS with radial defect. The presence of imperforate anus, stresses the importance of differential diagnosis with the TownesBrocks syndrome (TBS). A family, considered for a long time as an interesting example of OAVS, has been presently regarded as an example of TBS, after a baby was born with imperforate anus. Both the baby and his grandmother had radial anomalies. ${ }^{38}$ Two studies have, so far, reported a nonsense mutation in SALL1 in one patient with features of both TBS and hemifacial microsomia. ${ }^{39,40}$ The molecular analysis may be helpful in establishing a correct diagnosis for some cases, taking into account that mutation in the SALL1 gene causes TBS. ${ }^{41}$ Other important report concerns an unusual family in which affected individuals showed an 
extremely variable phenotype, consistent with the Okihiro syndrome, or hemifacial microsomia, or the isolated Duane anomaly. ${ }^{42}$ These studies indicate that not only SALL1 testing might be considered in some cases but SALL4 analysis is indicated as well. Other conditions with ear and/ or radial involvement, such as, the Nager syndrome (OMIM 154400), Holt-Oram syndrome (OMIM 142900), radial-renal syndrome (OMIM 179280), facioauriculoradial dysplasia (OMIM 171 480), Fanconi anemia (OMIM 257650 ), and VACTERL (OMIM 192350) association should be considered for differential diagnosis. ${ }^{10}$

\section{Conclusion}

In conclusion, we postulate that the patients presented with radial defects, inner ear malformation and sensorioneural hearing loss associated with anomalies of first and second branchial arches may characterize a new subset within OAVS, however, molecular analysis of SALL1 and SALL4 should be performed for exclusion of TBS and Okihiro syndrome. This study showed that this subset (OAVS with radial defect) had unknown etiology and sex ratio of $1 \mathrm{M}: 1 \mathrm{~F}$. Clinical findings such as low weight postnatal and short stature are part of the phenotypic spectrum of OAVS with radial defects. Concerning systemic anomalies, cardiac defects are the most frequent.

In relation to facial involvement, this subset presents, frequently, unilateral facial involvement, with the rightsided involvement in most cases, and the ipsilateral radial defect is usually observed. The high occurrence of structural inner ear malformation and sensorioneural hearing loss, observed in these patients, show that these findings are particular clinical signs of the OAVS with radial defects. Taking into account that some few cases with OAVS and radial defects were reported in mothers with a history of diabetes $^{21,23}$ and that pregnant women with pre-existing or gestational diabetes have a higher risk of giving birth to a child with malformations, ${ }^{43}$ special attention should be paid to maternal glicemia. Our study suggests that we are dealing with a new condition within the OAVS, however, molecular analysis of SALL1 and SALL4, to exclude TBS and Okihiro syndrome is essential to clarify this point.

\section{References}

1 Gorlin RJ, Cohen Jr MM, Hennekam RCM: Syndromes of the Head and Neck, 4th edn, Oxford university press: New York, 2001.

2 Cohen Jr MM, Rollnick BR, Kaye CI: Oculoauriculovertebral spectrum: an updated critique. Cleft Palate J 1989; 26: 276-286.

3 Wilson GN: Cranial defects in the Goldenhar syndrome. Am J Med Genet 1983; 14: $435-443$.

4 van den Ende JJ, van Bever Y, Richieri-Costa A: The OAV-spectrum and associated anomalies in 77 patients. Rev Bras Genet 1993; 16: 811-817.

5 Rollnick BR, Kaye CI, Nagatoshi K, Hauck W, Martin AO: Oculoauriculovertebral dysplasia and variants: phenotypic characteristics of 294 patients. Am J Med Genet 1987; 26: 361-375.
6 Sugiura Y: Congenital absence of the radius with hemifacial microsomia, ventricular septal defect and crossed renal ectopia. Birth Defects Orig Artic Ser 1971; 7: 109-116.

7 Moeschler J, Clarren SK: Familial occurrence of hemifacial microsomia with radial limb defects. Am J Med Genet 1982; 12: 371-375.

8 Oner N, Basaran ON, Yalcin O, Vatansever U, Acunas B: A newborn infant with left diaphragm agenesis, radial aplasia and preauricular appendices. Clin Dysmorphol 2004; 13: 59-60.

9 Essen-Moller E in: Harding AE, Hall CM, Baraitser M: Autosomal dominant asymmetrical radial dysplasia, dysmorphic facies and conductive hearing loss (facioauriculoradial dysplasia). J Med Genet 1982; 19: 110-115.

10 Online Mendelian Inheritance in Man, OMIM (TM). McKusickNathans Institute for Genetic Medicine, Johns Hopkins University (Baltimore, MD) and National Center for Biotechnology Information, National Library of Medicine (Bethesda, MD), 2000. World Wide Web URL: http://www.ncbi.nlm.nih.gov/omim/.

11 Gorlin RJ, Jue KL, Jacobsen U, Goldschmidt E: Oculoauriculovertebral dysplasia. J Pediatr 1963; 63: 991-999.

12 Mandelcorn MS, Merin S, Cardarelli J: Goldenhar's syndrome and phocomelia Case report and etiologic considerations. Am J Ophthalmol 1971; 72: 618-621.

13 Bowen DI, Collum LM, Rees DO: Clinical aspects of oculo-auriculo-vertebral dysplasia. Br J Ophthalmol 1971; 55: $145-154$.

14 Hodes ME, Gleiser S, DeRosa GP et al: Trisomy 7 mosaicism and manifestations of Goldenhar syndrome with unilateral radial hypoplasia. J Craniofac Genet Dev Biol 1981; 1: 49-55.

15 Wilson GN, Barr Jr M: Trisomy 9 mosaicism: another etiology for the manifestations of Goldenhar syndrome. J Craniofac Genet Dev Biol 1983; 3: 313-316.

16 Lessick M, Vasa R, Israel J: Severe manifestations of oculoauriculovertebral spectrum in a cocaine exposed infant. J Med Genet 1991; 28: 803-804.

17 van Bever Y, van den Ende JJ, Richieri-Costa A: Oculo-auriculovertebral complex and uncommon associated anomalies: report on 8 unrelated Brazilian patients. Am J Med Genet 1992; 44: $683-690$.

18 Gibson JN, Sillence DO, Taylor TK: Abnormalities of the spine in Goldenhar's syndrome. J Pediatr Orthop 1996; 16: 344-349.

19 Johnson JP, Poskanzer LS, Sherman S: Three-generation family with resemblance to Townes-Brocks syndrome and Goldenhar/oculoauriculovertebral spectrum. Am J Med Genet 1996; 61: 134-139.

20 Zelante L, Gasparini P, Castriota Scanderbeg A, Dimitri L, Criconia M, Gorlin RJ: Goldenhar complex: a further case with uncommon associated anomalies. Am J Med Genet 1997; 69: 418-421.

21 Ewart-Toland A, Yankowitz J, Winder A et al: Oculoauriculovertebral abnormalities in children of diabetic mothers. Am J Med Genet 2000; 90: 303-309.

22 Miura M, Sando I, Takasaki K, Haginomori S, Hirsch BE: Histopathologic study of temporal bone and eustachian tube in oculoauriculovertebral spectrum. Ann Otol Rhinol Laryngol 2001; 110: $922-927$.

23 Wang R, Martinez-Frias ML, Graham Jr JM: Infants of diabetic mothers are at increased risk for the oculo-auriculo-vertebral sequence: a case-based and case-control approach. J Pediatr 2002; 141: 611-617.

24 Pane M, Baranello G, Battaglia D et al: Severe abnormalities of the pons in two infants with Goldenhar syndrome. Neuropediatrics 2004; 35: 234-238

25 Castori M, Brancati F, Rinaldi R et al: Antenatal presentation of the Óculo-Auriculo-Vertebral Spectrum (OAVS). Am J Med Genet 2006; 140A: 1573-1579.

26 Kokavec R: Goldenhar syndrome with various clinical manifestations. Cleft Craniofac J 2006; 43: 628-634.

27 Meurman Y: Congenital microtia and meatal atresia. AMA Arch Otolatyng 1957; 66: 443-463. 
28 Tessier P: Anatomical classification of facial, cranio-facial and laterofacial clefts. J Max-Fac Surg 1976; 4: 69-92.

29 Katz J: Handbook of Clinical Audiology, 4th edn, Williams \& Wilkins Co.: Baltimore, 1994.

30 Poswillo D: The pathogenesis of the first and second branchial arch syndrome. Oral Surg Oral Med Oral Pathol 1973; 35: 302-328.

31 Salvado A, Rodriguez K, Guarisco JL: Hemifacial microsomia. J La State Med Soc 2003; 155: 136-141.

32 Opitz JM Faith GC: Visceral anomalies in a infant with the Goldenhar syndrome. Birth Defects Orig Artic Ser 1969; 5: $104-105$

33 Opitz JM, Utkus A: Comments on biological asymmetry. Am J Med Genet 2001; 101: 359-369.

34 Bisdas S, Lenarz M, Lenarz T, Becker H: Inner ear abnormalities in patients with Goldenhar syndrome. Otol Neurotol 2005; 26: $398-404$

35 Calzolari F, Garani G, Sensi A, Martini A: Clinical and radiological evaluation in children with microtia. Br J Audiol 1999; 33: $303-312$.

36 Rollnick BR, Kaye CI: Hemifacial microsomia and variants: pedigree data. Am I Med Genet 1983; 15: 233-253.

37 Tasse C, Bohringer S, Fisher S et al: Oculo-auriculo-vertebral spectrum (OAVS): clinical evaluation and scoring of 53 patients and proposal for a new classification. Eur I Med Genet 2005; 48 : 397-411.

38 Johnson JP, Poskanzer LS, Sherman S: Three-generation family with resemblance to Townes-Brocks syndrome and Goldenhar/ oculoauriculovertebral spectrum. Am J Med Genet 1996; 61: 134-139.

39 Kohlhase J, Taschner P, Burfeind $\mathrm{P}$ et al: Molecular analysis of SALL1 mutations in Townes-Brocks syndrome. Am J Hum Genet 1999; 64: 435-445.

40 Keegan CE, Mulliken JB, Wu BL, Korf BR: Townes-Brocks syndrome versus expanded spectrum hemifacial microsomia: review of eight patients and further evidence of a 'hot spot' for mutation in the SALL1 gene. Genet Med 2001; 3: 310-313.

41 Albrecht B, Liebers M, Kohlhase J: Atypical phenotype and intrafamiliar variability associated with a novel SALL1 mutation (Letter). Am J Med Genet 2004; 125A: 102-104

42 Terhal P, Rosler B, Kohlsase J: A family with features overlapping Okihiro syndrome, hemifacial microsomia and isolated Duane anomaly caused by a Novel SALL4 mutation. Am J Med Genet 2006; 140A: 222-226.

43 Nazer-Herrera J, Garcia-Huidobro M, Cifuentes-Ovalle L: Congenital malformations among offspring of diabetic women. Rev Med Chil 2005; 133: 547-554. 